University of Wollongong

Research Online

Faculty of Engineering and Information

Faculty of Engineering and Information

Sciences - Papers: Part A

Sciences

$1-1-2013$

Capability curve based enhanced reactive power control strategy for stability enhancement and network voltage management

Lasantha Meegahapola

University of Wollongong, lasantha.meegahapola@rmit.edu.au

Tim Littler

Queen's University of Belfast, t.littler@ee.qub.ac.uk

Sarath Perera

University of Wollongong, sarath@uow.edu.au

Follow this and additional works at: https://ro.uow.edu.au/eispapers

Part of the Engineering Commons, and the Science and Technology Studies Commons

Research Online is the open access institutional repository for the University of Wollongong. For further information contact the UOW Library: research-pubs@uow.edu.au 


\title{
Capability curve based enhanced reactive power control strategy for stability enhancement and network voltage management
}

\author{
Abstract \\ Reactive power has become a vital resource in modern electricity networks due to increased penetration \\ of distributed generation. This paper examines the extended reactive power capability of DFIGs to \\ improve network stability and capability to manage network voltage profile during transient faults and \\ dynamic operating conditions. A coordinated reactive power controller is designed by considering the \\ reactive power capabilities of the rotor-side converter (RSC) and the grid-side converter (GSC) of the DFIG \\ in order to maximise the reactive power support from DFIGs. The study has illustrated that, a significant \\ reactive power contribution can be obtained from partially loaded DFIG wind farms for stability \\ enhancement by using the proposed capability curve based reactive power controller; hence DFIG wind \\ farms can function as vital dynamic reactive power resources for power utilities without commissioning \\ additional dynamic reactive power devices. Several network adaptive droop control schemes are also \\ proposed for network voltage management and their performance has been investigated during variable \\ wind conditions. Furthermore, the influence of reactive power capability on network adaptive droop \\ control strategies has been investigated and it has also been shown that enhanced reactive power \\ capability of DFIGs can substantially improve the voltage control performance. ( $) 2013$ Published by \\ Elsevier Ltd.

\section{Keywords} \\ capability, enhancement, curve, network, voltage, management, enhanced, reactive, power, control, \\ strategy, stability

\section{Disciplines} \\ Engineering | Science and Technology Studies

\section{Publication Details} \\ L. Meegahapola, T. Littler \& S. Perera, "Capability curve based enhanced reactive power control strategy \\ for stability enhancement and network voltage management," International Journal of Electrical Power \\ and Energy Systems, vol. 52, (1) pp. 96-106, 2013.
}




\title{
Capability Curve based Enhanced Reactive Power Control Strategy for Stability Enhancement and Network Voltage Management
}

\author{
Lasantha Meegahapola ${ }^{*}$, Tim Littler², Sarath Perera ${ }^{1}$ \\ ${ }^{1}$ School of Electrical, Computer and Telecommunications Engineering, \\ University of Wollongong, Wollongong, 2500, Australia. \\ ${ }^{2}$ School of Electronics, Electrical Engineering and Computer Science, \\ The Queen's University of Belfast, Belfast, BT9 5AH, UK.
}

\section{Abstract}

Reactive power has become a vital resource in modern electricity networks due to increased penetration of distributed generation. This paper examines the extended reactive power capability of DFIGs to improve network stability and capability to manage network voltage profile during transient faults and dynamic operating conditions. A coordinated reactive power controller is designed by considering the reactive power capabilities of the rotor-side converter (RSC) and the grid-side converter (GSC) of the DFIG in order to maximise the reactive power support from DFIGs. The study has illustrated that, a significant reactive power contribution can be obtained from partially loaded DFIG wind farms for stability enhancement by using the proposed capability curve based reactive power controller; hence DFIG wind farms can function as vital dynamic reactive power resources for power utilities without commissioning additional dynamic reactive power devices. Several network adaptive droop control schemes are also proposed for network voltage management and their performance has been investigated during variable wind conditions. Furthermore, the influence of reactive power capability on network adaptive droop control strategies has been investigated and it has also been shown that enhanced reactive power capability of DFIGs can substantially improve the voltage control performance.

Keywords: Capability curve, doubly-fed induction generators (DFIG), droop control, reactive power, voltage stability, voltage control.

*Corresponding author contact details: Tel: +612 4221 3408, Fax: +61 242213236 and email: lasantha@uow.edu.au. 


\section{Introduction}

Wind power has become the most attractive renewable power source at present to achieve future renewable energy targets in power generation. Wind energy conversion technology has rapidly evolved during the last two decades and with the development of power electronic converter systems conventional induction generator based fixed-speed wind generators (FSWGs) have been superseded by power electronic based wind generation systems (e.g. doubly-fed induction generator (DFIG) and full-converter wind generator (FCWG)). The ability to control both active and reactive power and superior fault-ride through (FRT) capability are the main driving factors responsible for the popularity of power electronic based wind generator systems.

Power electronic based wind generators inherit substantial reactive power capability within their generator and converter systems. In particular, many researchers have shed light on DFIG reactive power capability characteristics and its reactive power limitations [1-2]. In the published literature a number of studies have proposed using the DFIG reactive power capability for transient stability enhancement [3-4], FRT improvement [4-5], system loss reduction [6-7], and to mitigate voltage fluctuations [8]. However, none of these studies have considered the DFIG reactive power capability characteristics within their control schemes and simple approximations have been made to determine the available reactive power capability from the DFIG. Consequently the reactive power capabilities of the DFIG have been underutilised for network performance enhancements.

Voltage rise issue has been considered as one of the major issues faced by the distribution network operators (DNOs) due to high penetration of renewable power generators (RPGs) in distribution networks [9-10]. Reactive power control has been proposed by many researchers as the main control approach to mitigate voltage rise issue in distribution networks. However, the extended reactive power capability of the RPGs has received less emphasis in these studies [9-10]. The droop control based approaches have been proposed in a number of studies; however these studies have assumed static capability curves for the RPGs [11]. Therefore, the importance of reactive power capability of the RPGs for voltage control must be further investigated in the context of the DFIG.

The novel contributions made in this study can be summarised as follows: A capability curve based reactive power controller is proposed for the DFIG, which can maximise the reactive power contribution from DFIG wind farms during dynamic operating conditions by generating dynamic capability characteristics for the DFIG. In particular, during partially loaded conditions a 
capability curve based reactive power controller can be effectively utilised as a vital dynamic reactive power resource for network stability enhancement. Moreover, the generator constraints of the DFIG have implicitly incorporated into the DFIG capability characteristics; hence it evades additional protection requirements to avert potential overloading conditions in the DFIG. In addition, a number of network adaptive droop control strategies have been developed using feeder characteristics, thus enabling effective use of the existing reactive power capability of the DFIG for voltage management.

This paper is organised as follows: The DFIG simulation model, reactive power capability characteristics and the coordinated reactive power controller are introduced in Section 2 . The performance of the proposed reactive power controller during transient grid faults is investigated in Section 3. The network adaptive droop control strategies and their performance are analysed during variable wind conditions in Section 4. Conclusions are presented in Section 5.

\section{DFIG Capability Curves and the Coordinated Reactive Power Controller}

\subsection{DFIG Simulation Model and Reactive Power Control Scheme}

A DFIG simulation model was developed in DIgSILENT Power Factory using a GE 1.5 MW wind generator [12]. The schematic of the DFIG simulation model is shown in Figure 1. The DFIG parameters are given in the Appendix. The steady-state performance of the dynamic simulation model was verified using measured data from a wind farm in the Northern Ireland [8].

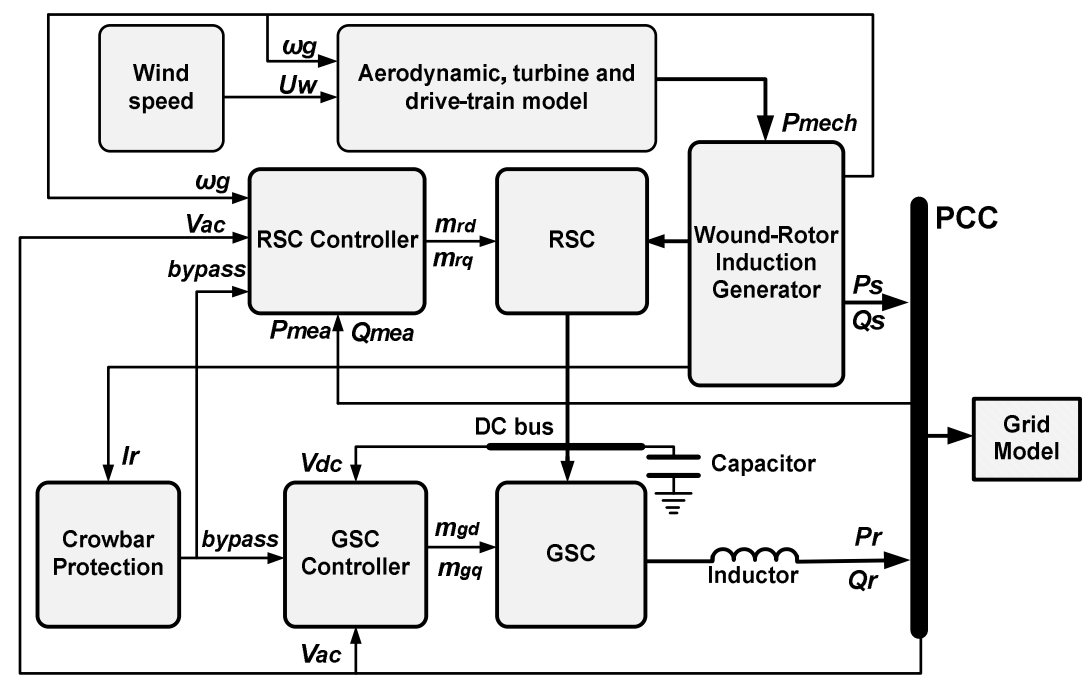

Figure 1: The DFIG Simulation Model [8]

A three-mass model (i.e. turbine, drive-shaft and generator inertia) has been used for the DFIG while the drive-train system was represented with finite shaft stiffness. The operation and control of DFIGs are well documented in the published literature [12-13], thus for brevity the simulation 
model will not be discussed here. It is imperative to discuss the reactive power control scheme, as this paper proposes an enhanced reactive power controller for a DFIG. The RSC and GSC reactive power controllers comprise of two control schemes: a slow controller and fast current controller. In terms of the GSC an additional droop is implemented within the slow controller, since both controllers control the reactive power at the PCC (see Figure 2).

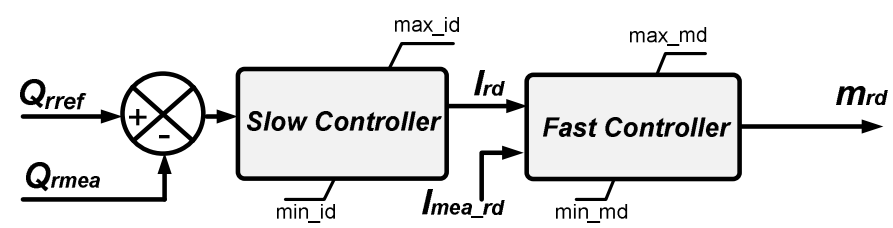

(a)

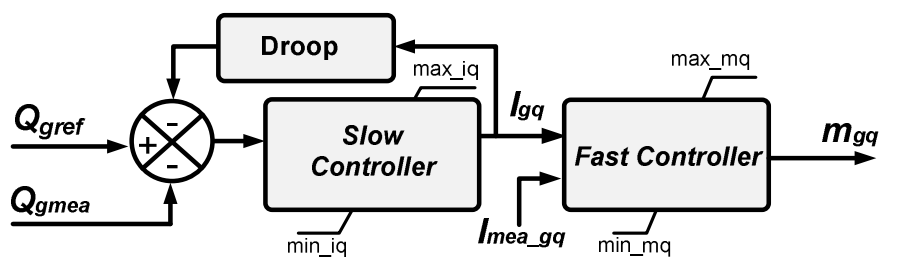

(b)

Figure 2: DFIG Reactive power control schemes; (a) RSC controller, (b) GSC controller.

As illustrated in Figure 2, the difference between the reactive power references (i.e. Grref and Qgref) and the reactive power measurements (i.e. Brmea and Ggmea) are calculated within the slow controller and fed through the internal PI controller to generate the appropriate current references (i.e. $I_{r d}$ and $\left.I_{g q}\right)$. It should be noted that in terms of the RSC controller, the rotor currents are determined in the stator-flux oriented reference frame; hence the d-axis component of the rotor current can be controlled in order to control the reactive power. However, in terms of the GSC controller the q-axis current component is controlled in order to control the reactive power. Once the corresponding current references are determined they are compared with the corresponding measured current components and used to generate the required modulation indices (i.e. $m_{r d}$ and $\left.m_{g q}\right)$ for the converters (i.e. RSC and GSC). Furthermore, it should be noted that the DIgSILENT Power Factory power electronic converter models are built based on separate modulation indices for both $d$-axis and q-axis, hence they must be calculated separately by the controller in order to independently control the active and reactive power.

The reactive power references (i.e. $Q_{r r e f}$ and $Q_{g r e f}$ ) are generated based on the control strategy used for the wind generator (i.e. voltage and power factor control). The existing reactive power capability ( $\left.Q_{c c}\right)$ of the DFIG is determined based on apparent power of the generator (S) and active power $(P)$ output (i.e. $Q_{c c}=\sqrt{S^{2}-P^{2}}$ ); hence it under estimate the reactive power capability of the 
DFIG. In addition, the GSC reactive power capability has not been used for reactive power control purposes, except during grid disturbances [5]. The proposed capability curve based reactive power controller will dynamically determine the reactive power capability for the DFIG during variable speed operation; hence enhanced reactive power capability can be obtained from the DFIG to fulfil the necessary network requirements.

\subsection{DFIG Reactive Power Capability Characteristics}

The reactive power capability of the DFIG can be accredited to both the RSC and the GSC. The reactive power capability charts were derived considering the limiting factors and the methodology outlined in [1-2] for the GE 1.5 MW DFIG (see Figure 3).

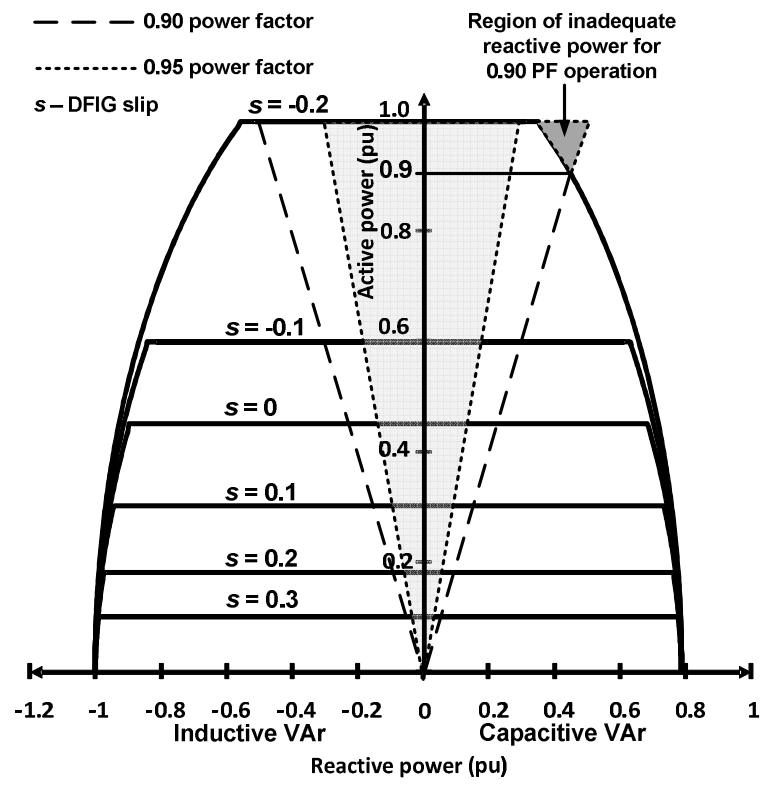

(a)

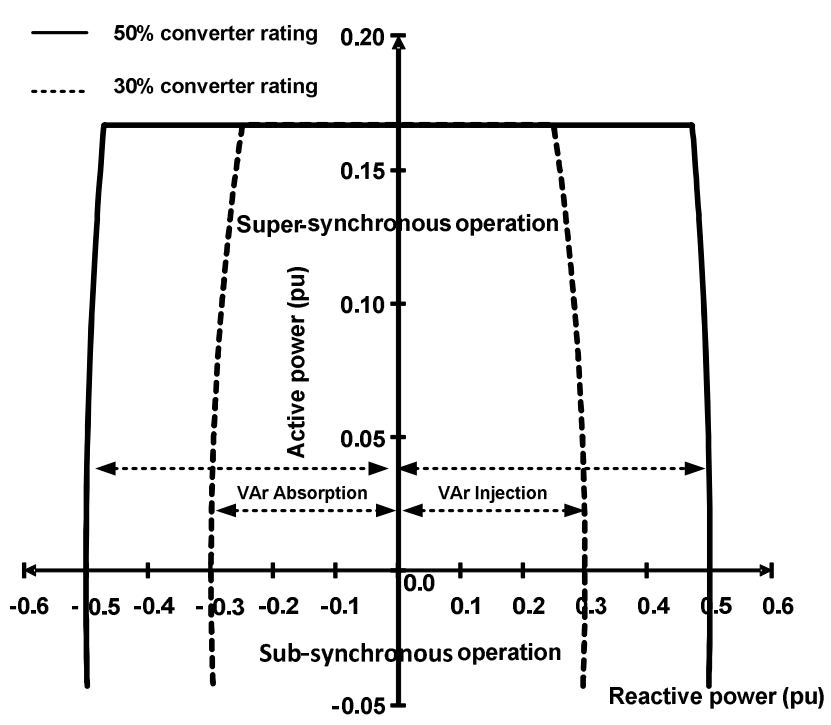

(b)

Figure 3: DFIG Capability Curves; (a) RSC, (b) GSC.

The RSC reactive power capability is mainly constrained by the stator current, rotor current and rotor voltage limits [1-2]. These limiting factors further depend on the operating slip of the machine, and hence individual capability curves were produced for several values of slip. The RSC is capable of operating between +0.95 to -0.95 power factor across the full active power range of the DFIG without additional reactive power support from the GSC. However, 0.90 lagging power factor operation reactive power capability is limited to $0.90 \mathrm{pu}$ active power output, hence additional reactive power must be provided by the GSC during such conditions.

The GSC reactive power capability is mainly limited by the DC link and the back-to-back converter ratings, which was derived based on the method outlined in [2]. The GSC capability chart indicates \pm 0.28 pu average reactive power capability for a $30 \%$ converter rating across its 
full operating range while for a 50\% converter rating the average reactive power capability increases to $\pm 0.48 \mathrm{pu}$. Therefore, a $50 \%$ converter rating indicates a combined reactive power capability of $1.28 \mathrm{pu}$ during zero active power production. However, during full active power production this reduces to $0.83 \mathrm{pu}$.

\subsection{Coordinated Reactive Power Controller}

The coordinated reactive power controller was designed using the RSC as the main controller with the GSC acting as the auxiliary controller (assuming 50\% converter rating). The coordinated control scheme between the GSC and RSC is shown in Figure 4. The capability curves were implemented in DIgSILENT Power Factory using the dynamic simulation language (DSL) together with the coordinated reactive power controller. When deriving the capability characteristics of the DFIG, internal generator constraints such as stator current limit, rotor current limit and rotor voltage limit have been implicitly incorporated in the derivation, thus controller itself can adopt to safe operating conditions while delivering maximum reactive power and excluding the possibility of potential overload during fault conditions. The reactive power capability of the RSC for the intermediate slip values (i.e. other than the slip values shown in Figure 3-(a)) were calculated employing a linear approximation function in DIgSILENT Power Factory.

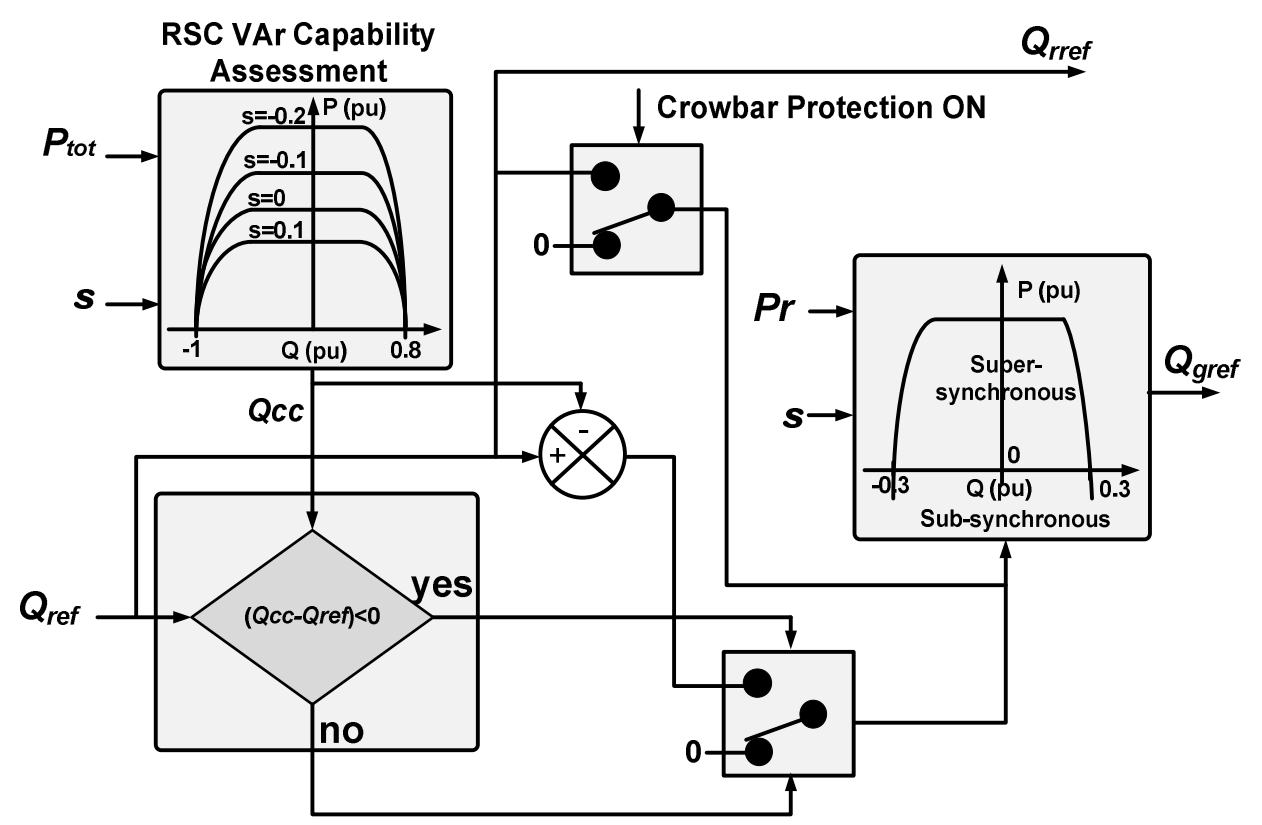

Figure 4: Coordinated reactive power controller.

The RSC reactive power capability of the RSC $\left(Q_{c c}\right)$ is determined based on the capability curve of Figure 3-(a), the total active power output $\left(P_{t o t}\right)$ and operating slip $(s)$ of the DFIG. Then $Q_{c c}$ is compared against the reactive power reference $\left(Q_{r e f}\right)$ dictated by the reactive power control scheme 
of the DFIG. The excess reactive power requirement becomes the reactive power reference for the GSC (Ggref). Therefore, the GSC is operated at unity power factor unless the reactive power requirement exceeds the RSC reactive power capability. The reactive power reference is determined based on the control strategy of the DFIG (i.e. voltage and power factor control, flicker mitigation). During transient disturbances the reactive power reference is determined considering the voltage drop at the DFIG terminal in order to ride-through fault. The reactive power reference $\left(Q_{r e f}\right)$ is used as the reactive power reference for the RSC $\left(Q_{r r e f}\right)$, since the RSC depicts higher reactive power capability over the GSC, and is selected as the main reactive power controller for the proposed control scheme. Moreover, when the crowbar operates (i.e. during large transient disturbances) the RSC can no longer provide reactive power, and hence the reactive reference (Qref) is used as the reactive power reference for the GSC. The control performance of the coordinated reactive power controller was analysed during a three-phase short-circuit fault when operating at its maximum super-synchronous speed (1.2 pu) using the test network model in [8].
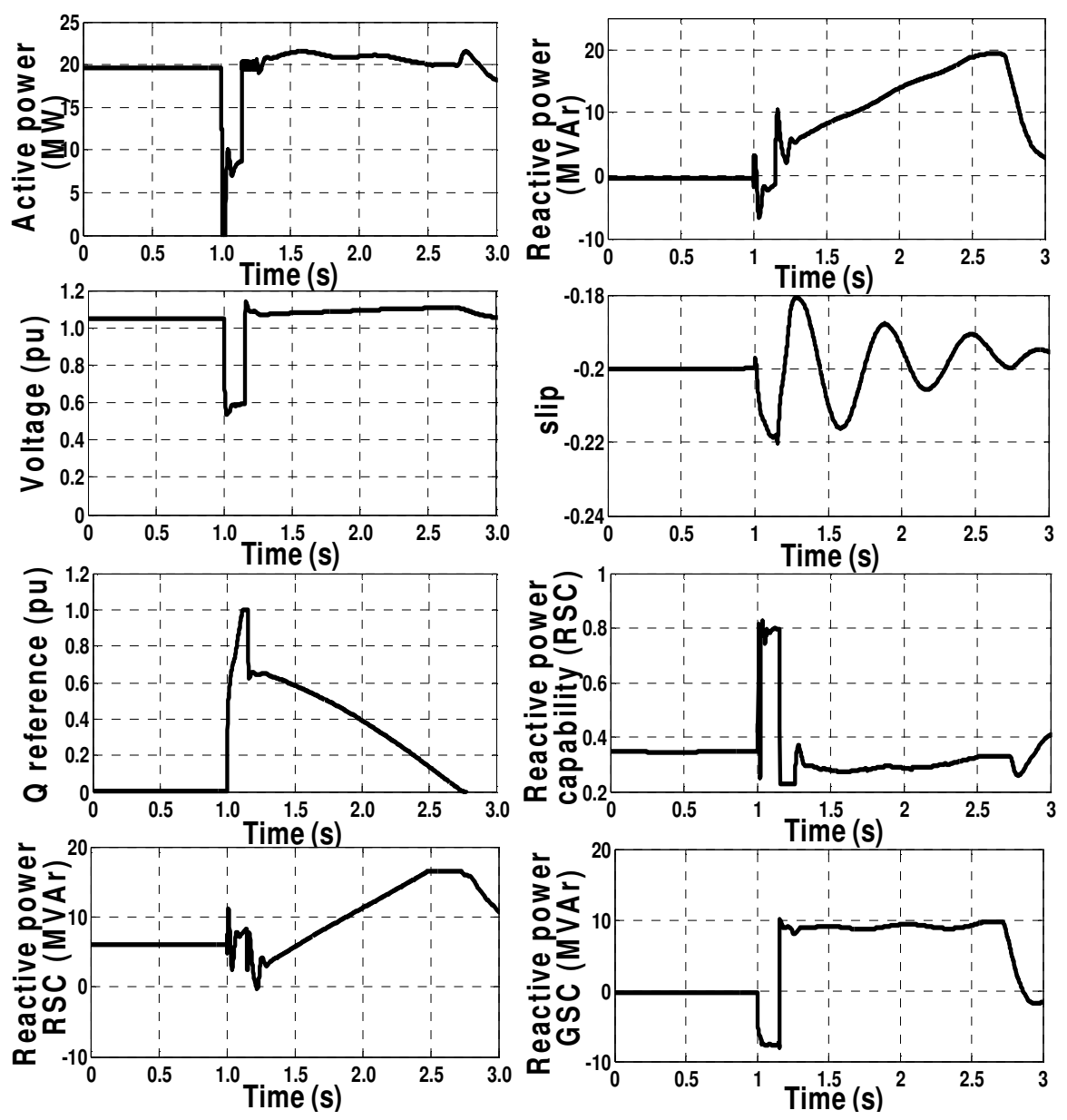

Figure 5: Performance of the coordinated reactive power controller.

According to Figure 5 the DFIG RSC dispatches reactive power based on its capability curves in Figure 3, while the excess reactive power requirement is provided by the GSC. During the fault 
the DFIG terminal voltage reduces and consequently the DFIG active power output has substantially reduced from its steady-state operating conditions. This results in an improvement in RSC reactive power capability (see Figure 3-(a)) arising as a result of the DFIG active power reduction. While the voltage controller demands high reactive power output from the DFIG in order to improve the terminal voltage, this requirement exceeds the RSC reactive power capability. Subsequently, the excess reactive power demand (0.6-0.7 pu) is diverted to the GSC to meet the total reactive power requirement.

\section{Transient Stability Performance}

\subsection{Test System Configuration}

A transient stability study was conducted using the New England 39 bus system which comprised three network regions interconnected by four major tie-lines (see Figure 6). The synchronous generators were represented by different plant models (i.e. gas, steam, and hydro) in existing systems. The exciter models were based on the standard IEEE models [14]. The power system stabilisers (PSSs) were installed in generators at buses 34, 36 and 38, since these buses identified as the optimal locations to damp inter-area mode oscillations in the original network [15-16]. The governor droop was set at $4 \%$ for all synchronous machines, and the automatic voltage regulators (AVRs) were set to regulate the terminal voltage of the synchronous generators.

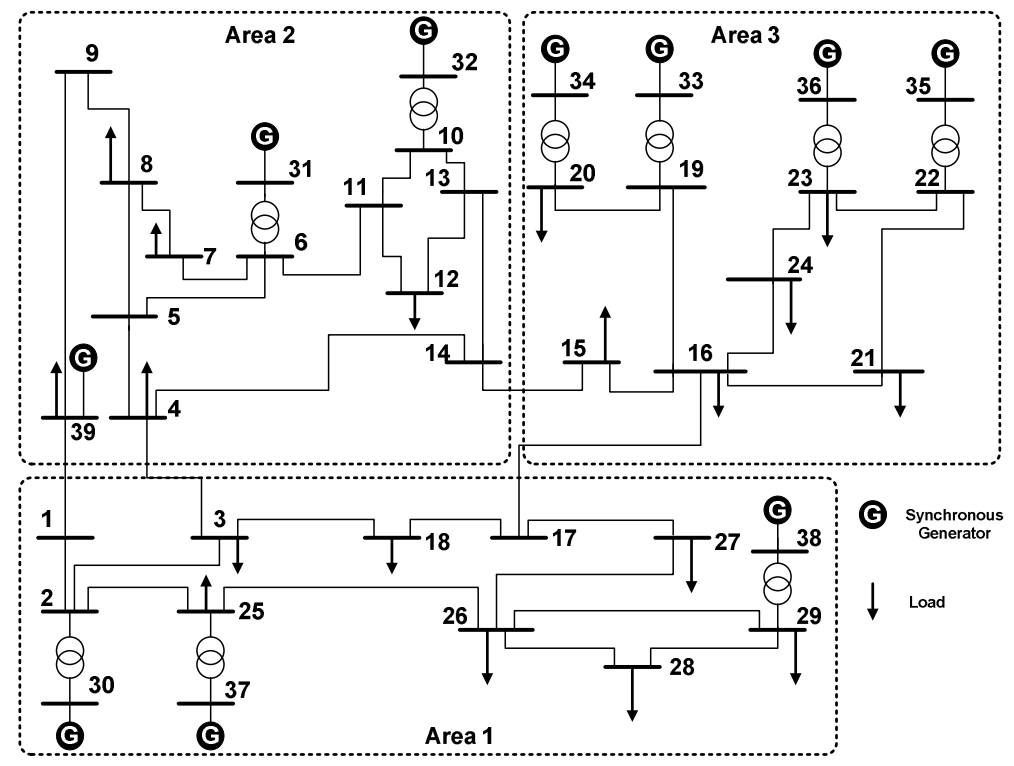

Figure 6: New England 39 bus system.

\subsection{Voltage Recovery and Maximum Rotor Angle Deviation}

The voltage recovery time and maximum rotor angle deviation [17-18] were used as the main determinants to evaluate network stability performance. In the maximum rotor angle difference 
method, the maximum angle separation between synchronous machines in the network will be calculated in a common reference frame. Therefore, it can be considered as a holistic approach to determine transient stability of the network. Moreover, when a large rotor angle separation occurs in the network it will result in rapid voltage decrease at intermediate points of the network, hence it can implicitly determine the voltage stability of the network [19].

The existing synchronous generator units installed at buses 32,35 and 37 were replaced by DFIG based wind farms. However, the DFIGs were operated at unity power factor. A 150 ms threephase short-circuit fault was applied at three different locations (i.e. 2, 11, 19) in the network while representing each region. The voltage profile and maximum rotor angle separation between synchronous generators were measured following the fault. Four operating strategies were investigated; no voltage support, RSC support, GSC support and both RSC and GSC reactive power support. The dynamic behaviour of DFIG wind turbine systems during network faults are well researched in the published literature, thus main focus of the discussion is limited to stability enhancement from the proposed reactive power controller [20-21]. Table 1 illustrates the voltage recovery time after applying a three-phase short-circuit fault (with $0.5 \Omega$ fault impedance) in three different fault locations in the network. Furthermore, it was assumed that DFIGs operated at sub-synchronous $(0.8 \mathrm{pu})$ speed prior to the fault.

Table 1: Voltage Recovery Time

\begin{tabular}{c|c|c|c|c}
\hline \hline Faulted bus & $\begin{array}{c}\text { Without voltage } \\
\text { support }\end{array}$ & RSC support & GSC support & $\begin{array}{c}\text { RSC and GSC } \\
\text { support }\end{array}$ \\
\hline B2 & $0.41 \mathrm{~s}$ & $0.16 \mathrm{~s}$ & $0.17 \mathrm{~s}$ & $0.16 \mathrm{~s}$ \\
\hline B11 & $0.38 \mathrm{~s}$ & $0.16 \mathrm{~s}$ & $0.17 \mathrm{~s}$ & $0.15 \mathrm{~s}$ \\
\hline B19 & $0.48 \mathrm{~s}$ & $0.40 \mathrm{~s}$ & $0.43 \mathrm{~s}$ & $0.39 \mathrm{~s}$ \\
\hline \hline
\end{tabular}

According to Table 1, the voltage recovery time has significantly improved by utilising the extended reactive power capability of the DFIG (i.e. RSC and GSC capability). In particular, when the reactive capability of both the RSC and GSC are utilised voltage recovery time has improved by $61 \%$ compared to a scenario with no voltage support for a fault at B2 (see Figure 7 -(a)). In addition, the severity of the voltage dip during the fault at B2 has also been reduced by $18 \%$ when the reactive power capability of both converters is used for dynamic voltage support (see Figure 7(a)). Consequently, the maximum rotor angle deviation has also recovered quickly to steady-state value compared to other scenarios (see Figure 7-(b)). 


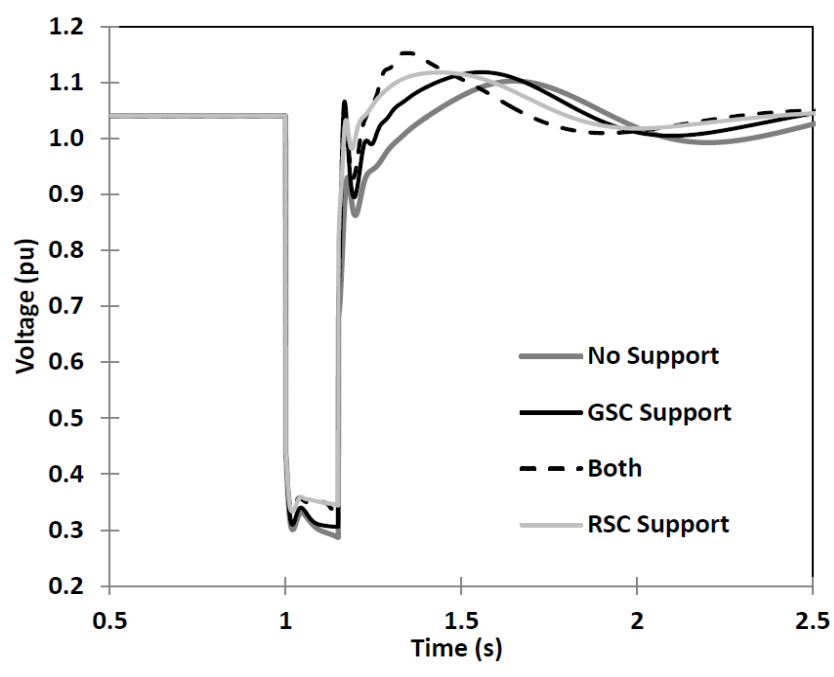

(a)

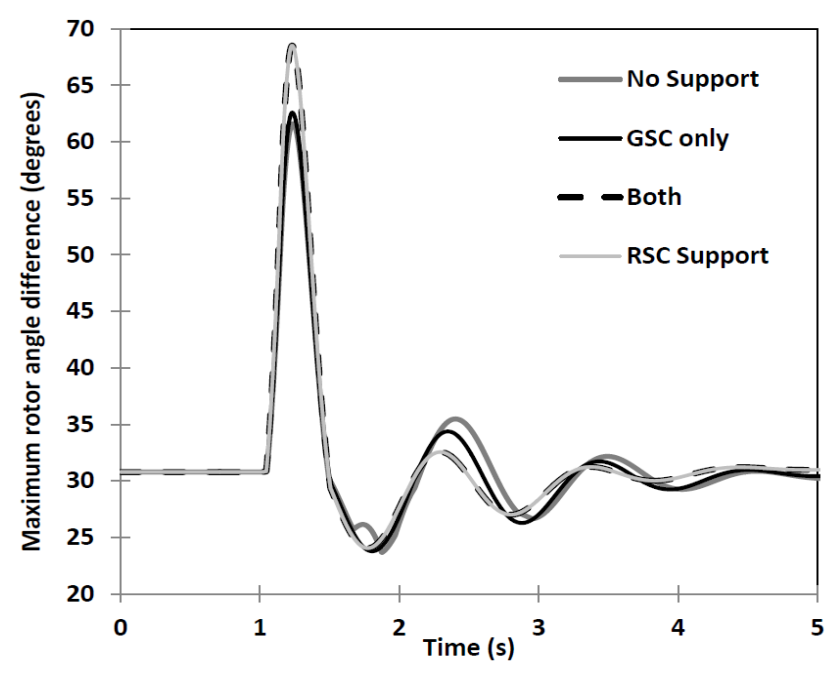

(b)

Figure 7: Network performance during a transient fault with different reactive power capabilities; (a) Voltage variation at bus 2, (b) Maximum rotor angle difference.

In order to further examine the effectiveness of the proposed strategy, the DFIG wind farms were operated at the same reactive power output similar to those of the replaced synchronous generator units (i.e. 32, 35 and 37). The same faults (i.e. 2, 11, and 19) were applied to the network and monitored voltage profiles and maximum rotor angle deviations across the network. The results have shown almost identical performance as depicted in Figure 7 (results are not shown) which reconfirm the performance improvements. In order to further validate the transient stability improvement due to extended reactive power capability of the DFIG, modal analysis was conducted on New England-39 system after clearing a fault at bus 19. The system eigenvalues under four different reactive power capabilities for the DFIG are illustrated in Figure 8.

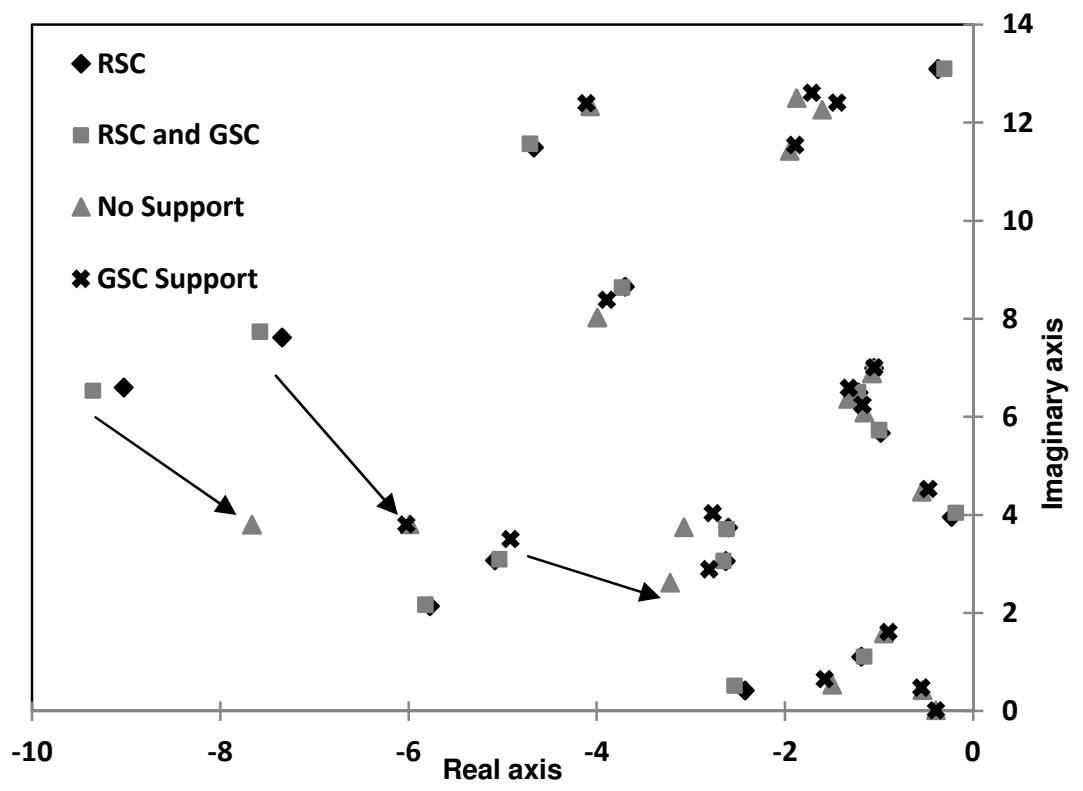

Figure 8: New England-39 system eigenvalues under different reactive power control strategies. 
According to Figure 8, eigenvalues have moved towards the positive real axis, when reactive power capability of the DFIG is decreased. Therefore, it reconfirms the stability improvement due to extended reactive power capability of the DFIG.

\subsection{Impact of Generator Loading}

The generator loading will also impact on the reactive power capability of the DFIG. Therefore, the impact of generator loading on transient stability was investigated under three different loading conditions for the DFIG. Table 2 illustrates the average reactive power dispatch following a fault (three-phase short-circuit with $0.5 \Omega$ fault impedance) until voltage recovers to a steady-state value for the three operating conditions (a fault in each area). The average reactive power output during post-fault period is shown in Table 2 .

Table 2: Reactive Power Dispatch during Fault Conditions

\begin{tabular}{c|c|c|c}
\hline \hline $\begin{array}{c}\text { Generator } \\
\text { Loading }\end{array}$ & DFIG 32 & DFIG 35 & DFIG 37 \\
\hline $67 \%$ & $540 \mathrm{MVAr}$ & $249 \mathrm{MVAr}$ & $463 \mathrm{MVAr}$ \\
\hline $83 \%$ & $480 \mathrm{MVAr}$ & $230 \mathrm{MVAr}$ & $424 \mathrm{MVAr}$ \\
\hline $100 \%$ & $474 \mathrm{MVAr}$ & $189 \mathrm{MVAr}$ & $410 \mathrm{MVAr}$ \\
\hline \hline
\end{tabular}

Each loading condition corresponds to different operating speeds of the DFIG (i.e. $0.8 \mathrm{pu}, 1 \mathrm{pu}$, and $1.2 \mathrm{pu}$ ). According to Table 2 the highest reactive power output was dispatched when the DFIG operated at sub-synchronous speed (i.e. 0.67\% loading), since the DFIG has a much larger reactive power reserve under partially loaded conditions. This improvement is further evident from Figure 9, which illustrates the dynamic variation of the reactive power capability characteristics of the DFIG at bus 37 for different operating conditions during a three-phase short-circuit fault. 


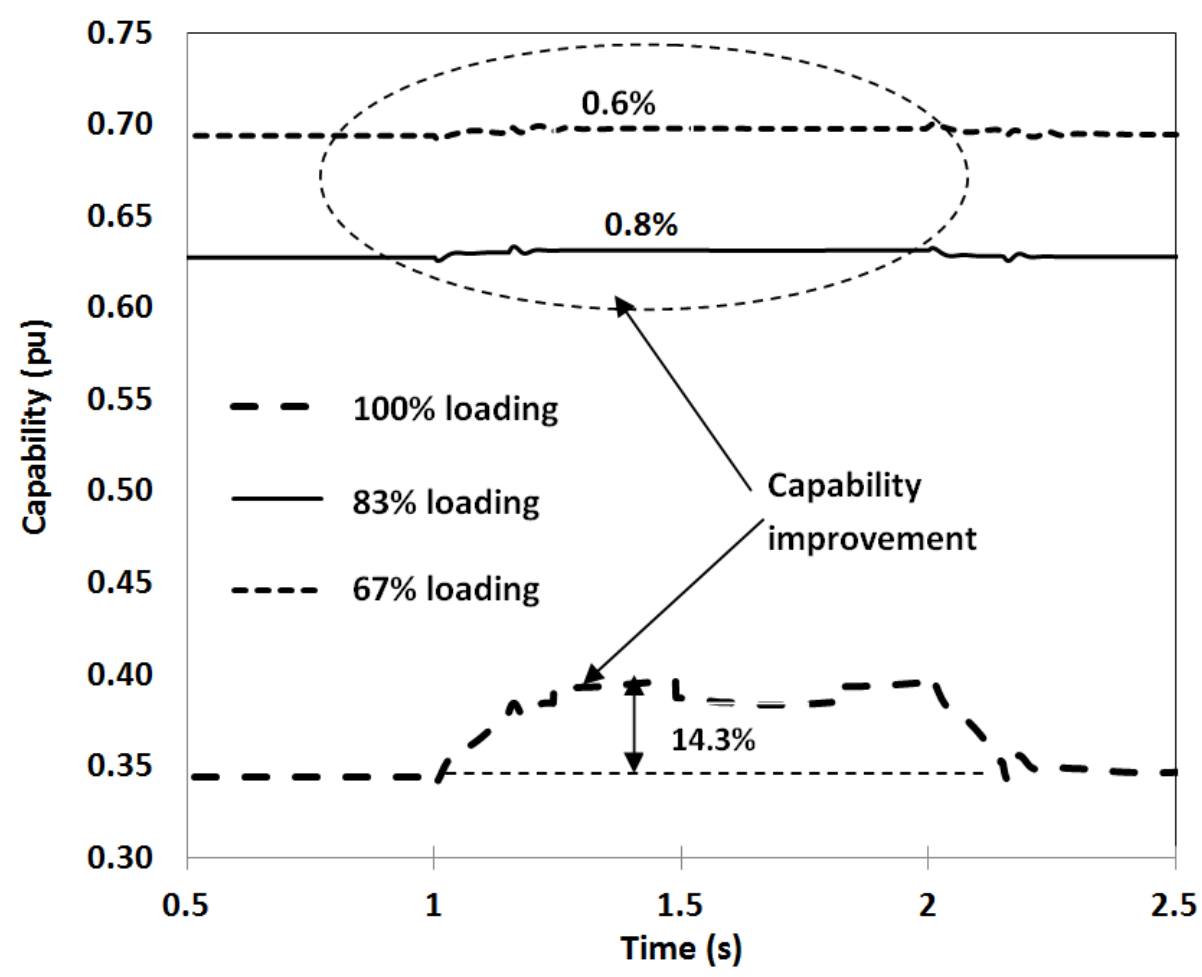

Figure 9: Dynamic reactive power capability variation of the DFIG at bus 37 (during a fault at bus 2) under different operating conditions.

According to Figure 9, during partially loaded conditions the DFIG depicts higher reactive power capability; hence DFIGs can provide enhanced reactive power support during system contingencies to improve network stability. However, for $100 \%$ loading reactive power capability has significantly improved (by 14.3\%) during the post fault period compared to partially loaded conditions. This is due to the fact that DFIGs experience a large active power reduction during grid faults when operated at $100 \%$ loading compared to partially loaded conditions [4], hence its reactive power capability will improve substantially during the fault. Therefore, the capability curve based reactive power control approach provides enhanced stability support during system contingencies.

\section{Distribution Feeder Voltage Control}

Droop control was proposed as one of the feasible methods to control voltage when multiple generating sources are connected to distribution feeders. Network adaptive droop control strategies were developed based on network characteristics and generator proximity to distribution transformer. This section evaluates the performance of different droop control strategies and their performance impact that arise as a result of the reactive power capability of the DFIG in the context of the voltage rise in a distribution feeder during high wind power generation. 


\subsection{Network Adaptive Droop Control}

Consider a generator feeding active and reactive power to an external grid via a distribution line with line resistance of $R_{l}$ and reactance of $X_{l}$. The voltage fluctuation $(\Delta V)$ due to variable active and reactive power output from a grid connected generator can be denoted as follows [8]:

$$
\Delta V=\frac{R_{l}(\Delta P)+X_{l}(\Delta Q)}{V_{g}}
$$

where $V_{g}$ is the generator voltage at the PCC. If the generator is operating at unity power factor, voltage variation is governed by the active power variation only.

$$
\Delta V=\frac{R_{l}(\Delta P)}{V_{g}} \Rightarrow \Delta V=\left(\frac{R_{l}}{V_{g}}\right) \Delta p
$$

If voltage fluctuations due to active power variations are compensated by reactive power, reactive power $(\Delta Q)$ variation can be expressed as follows:

$$
\Delta Q=\left|\frac{R_{l}(\Delta P)}{X_{l}}\right|
$$

If droop control is used then $\Delta Q$ can be denoted as follows:

$$
\Delta Q=\frac{1}{n} \Delta V
$$

where droop constant ( $n$ ) can be derived using (3) and (4);

$$
\frac{1}{n}=\left(\frac{R_{l}}{X_{l}}\right)\left(\frac{\Delta P}{\Delta V}\right)
$$

From (5) and (2) droop can be determined as:

$$
\frac{1}{n}=\frac{V_{g}}{X_{l}} \Rightarrow n=\frac{X_{l}}{V_{g}}
$$

In (6) the line reactance component $\left(X_{l}\right)$ depends on the generator location. The voltage $V_{g}$ can be determined based on the allowable grid-code voltage variation for the feeder and the generator proximity to distribution transformer. In order to obtain a much greater response from wind generators located at close proximity to the distribution transformer (in order to avoid reactive power burden on remote generators) the droop constant must be set at a lower value. Therefore, desirable voltage at the $i^{\text {th }}$ generator $\left(V_{g i}\right)$ can be determined based on the following relationship:

$V_{g i}=\left(V_{u}-\frac{\Delta V_{a l}}{L} l\right)$ 
$V_{u}$ is the upper voltage limit defined by the grid code. $\Delta V_{a l}$ is the allowable voltage range between nominal system voltage and grid-code upper voltage limit. $L$ is the total length of the feeder and $l$ is the distance to the generator from the transformer. From (6) and (7) the voltage droop can be determined for a generator as follows:

$n=\left(\frac{x l}{\left(V_{u}-\frac{\Delta V_{a l}}{L} l\right)}\right)$

where $x$ is the line reactance per unit length of the feeder. The reactance term $\left(X_{l}=x l\right)$ in (8) depends on the location of the generator, hence droop is minimum when closer to the transformer while the generator located at the remote end of the feeder has the highest droop. Ultimately, generators which are sited at close proximity to the distribution transformer are more responsive to voltage variations; hence they have the highest reactive power response. Typically, voltage rise issues occur at the remote end of the feeder when all the generators are operating at their highest active power output. Therefore, according to (3), generators at the remote end of the feeder should provide substantial reactive power response compared to generators closer to the distribution transformer. Therefore, (8) will ensure fair distribution of reactive power response between RPGs installed in the distribution feeder. In addition, the activation voltage for the droop control scheme at the $i^{\text {th }}$ generator $\left(V_{\text {set_gi }}\right)$ is determined based on the following relationship:

$V_{\text {set_gi }}=\left(V_{u}-\frac{\Delta V_{a l}}{L}(L-l)\right)$

According to (9), the generators which are sited at close proximity to the distribution transformer have an activation voltage closer to the nominal system voltage, while the most remote generator activates at a higher voltage. This will enable DFIGs which are sited at close proximity to the distribution transformer to respond first during a voltage increase in the distribution feeder, hence reactive power burden on remote DFIGs can be further relieved, since during high wind conditions voltage rise issues are likely to occur at remote locations in the distribution feeder. In order to analyse the droop control strategies for the DFIG wind generators, the medium voltage (MV) distribution feeder shown in Figure 10 was considered. 


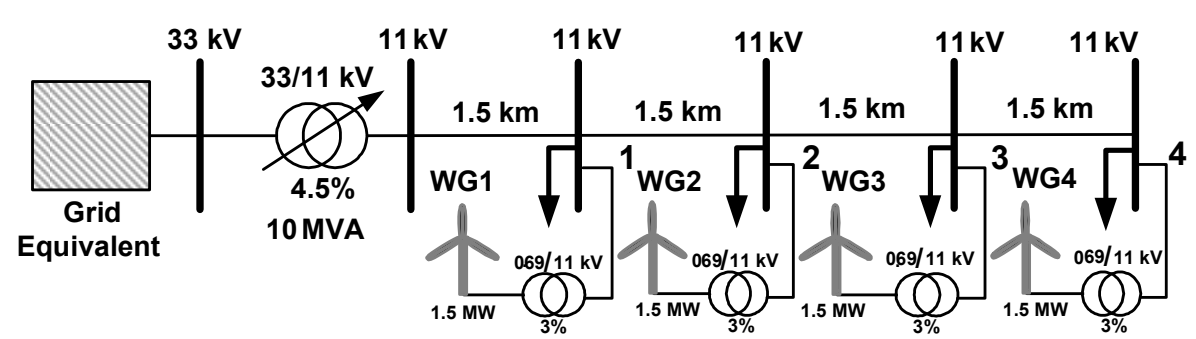

Figure 10: The $11 \mathrm{kV}$ distribution feeder model.

The distribution feeder shown in Figure 10 is a $6 \mathrm{~km}$ long feeder which has a reactance of $0.31 \Omega / \mathrm{km}$ and resistance of $0.3 \Omega / \mathrm{km}$. In this study it was assumed that the maximum voltage limit was $1.05 \mathrm{pu}$, hence an allowable upper voltage range $\left(\Delta V_{a l}\right)$ is $0.05 \mathrm{pu}$. The loads were aggregated to $11 \mathrm{kV}$ nodes in the feeder and assumed that each aggregated load consumes 0.2 MW and operates at 0.85 lagging power factor. A 1.5 MW the DFIG wind generator was connected to each node of the $11 \mathrm{kV}$ feeder. These values replicate the characteristics of a typical $11 \mathrm{kV}$ MV feeder [22]. Furthermore, the transformer tap setting was adjusted in order to maintain the feeder voltage level within the grid code limits, hence it is unlikely to cause any under voltage condition (i.e. below $0.95 \mathrm{pu}$ ) in the feeder during high load and low wind generation. Following droop control strategies were investigated in this study.

- Strategy 1: Identical droop and activation voltage for each DFIG

- Strategy 2: Network adaptive droop and identical activation voltage for each DFIG

- Strategy 3: Identical droop and network adaptive activation voltage for each DFIG

- Strategy 4: Network adaptive droop and activation voltage for each DFIG

It should be noted that Strategies 1 to 4 were derived considering the network adaptive droop and activation voltage, in order to determine the most feasible voltage droop and activation voltage for DFIGs. The network adaptive droop was determined based on (8) while the network adaptive activation voltage was determined based on (9). For Strategy 1, the droop was set at 0.45 based on the network location of WG1 and the activation voltage was set at $1 \mathrm{pu}$ based on the activation value calculated for the most remote location. The droop settings for each droop control strategy are shown in Table 3. 
Table 3: Droop Control Settings for Wind Generators

\begin{tabular}{|c|c|c|c|c|c|c|c|c|}
\hline \multirow{2}{*}{ 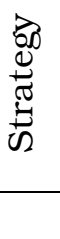 } & \multicolumn{4}{|c|}{ Droop $(n)$} & \multicolumn{4}{|c|}{ Activation Voltage (pu) } \\
\hline & WG1 & WG2 & WG3 & WG4 & WG1 & WG2 & WG3 & WG4 \\
\hline 1 & 0.45 & 0.45 & 0.45 & 0.45 & 1 & 1 & 1 & 1 \\
\hline 2 & 0.45 & 0.91 & 1.38 & 1.86 & 1 & 1 & 1 & 1 \\
\hline 3 & 0.45 & 0.45 & 0.45 & 0.45 & 1.013 & 1.025 & 1.038 & 1.05 \\
\hline 4 & 0.45 & 0.91 & 1.38 & 1.86 & 1.013 & 1.025 & 1.038 & 1.05 \\
\hline
\end{tabular}

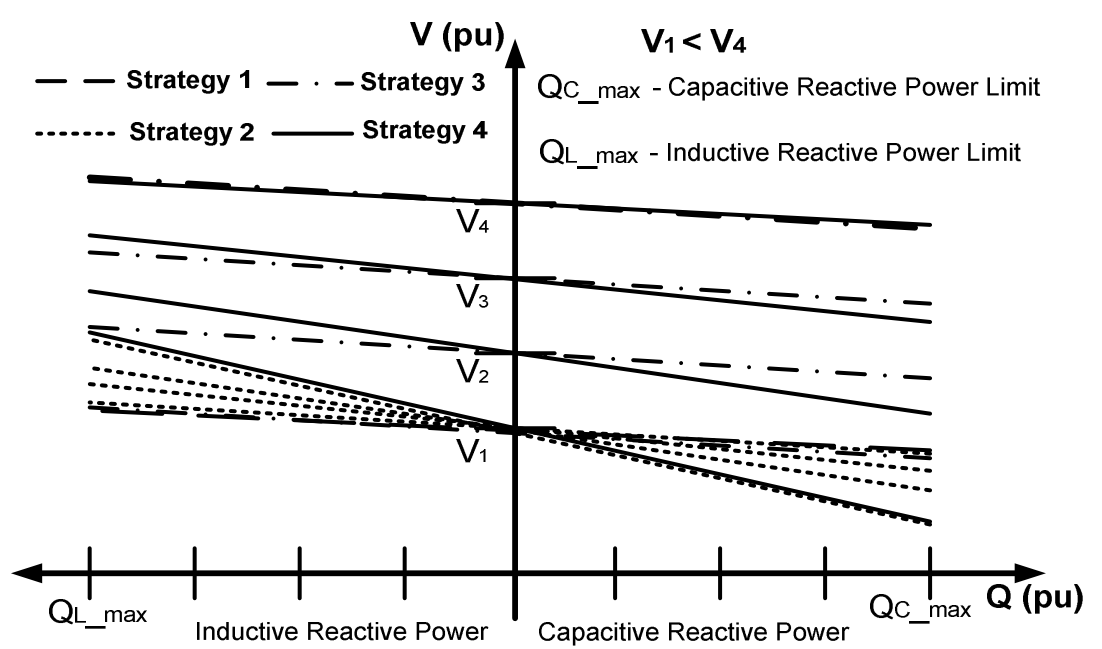

Figure 11: Comparison of reactive power capability for droop control strategies.

Figure 11 illustrates the voltage and reactive power characteristics for each droop control strategy. $\mathrm{V}_{1}$ to $\mathrm{V}_{4}$ represent different voltage droop activation voltages. The voltage droop activation voltage for Strategy 1 is $V_{1}$ where its value was based on the nominal system voltage. In terms of Strategies 3 and 4, different voltage droop activation voltages were determined based on (9), while $V_{1}$ was assigned to the closest DFIG from the distribution transformer, while $V_{4}$ assigned to the most remote DFIG from the transformer.

\subsection{Dynamic Network Voltage Management}

The dynamic performance was analysed based on wind power variations over a 10 minute time period (600 s). All wind generators in the distribution feeder were assumed to have the same active power profile, where their active power output varied from $1.4 \mathrm{MW}$ to $0.85 \mathrm{MW}$ during variable wind conditions. It was assumed that all four generators experienced the same wind profile; hence they generate the same active power output during the 10 minute period. Figure 12 
illustrates the voltage variation and reactive power variation for WG1 during dynamic operating conditions.

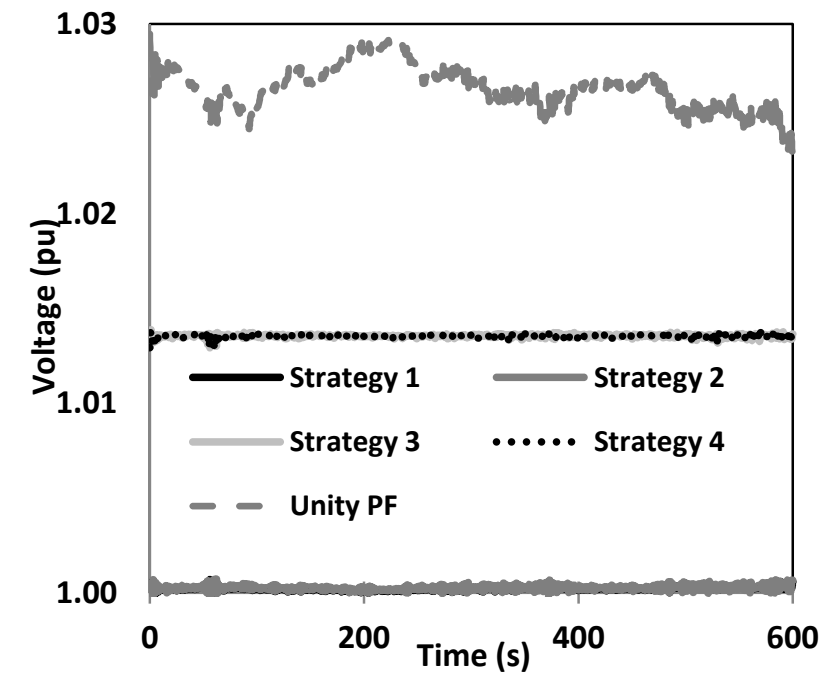

(a)

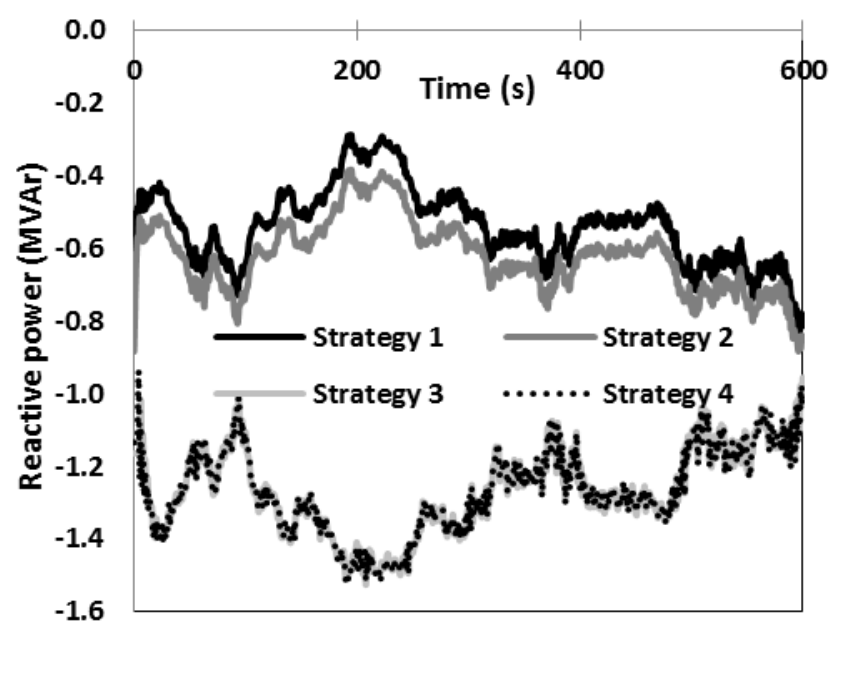

(b)

Figure 12: Dynamic performance of WG1; (a) Voltage at bus 1, (b) Reactive Power.

The droop control strategies have depicted significantly reduced voltage fluctuations compared to unity power factor operation. However, WG1 indicates higher average steady-state voltage and reactive power requirement for Strategies 3 and 4 compared to Strategies 1 and 2. This can be explained as follows: droop control Strategies 3 and 4 have higher droop control activation voltage than Strategies 1 and 2, therefore DFIGs activate their voltage control mechanism at a higher voltage than the nominal system voltage. As exemplified in the Section 4.1, the droop constant and the activation voltage were calculated (for Strategies 3 and 4) based on the distribution feeder characteristics. For example, the droop activation voltage for WG1 is $1.013 \mathrm{pu}$ and the corresponding value for WG4 is $1.05 \mathrm{pu}$. This has resulted in location based reactive power response from DFIGs, leading to a difference in steady-state voltage profiles for Strategies 3 and 4 compared to Strategies 1 and 2.

The location based reactive power response variations can be further observed from Figure 13, which illustrates the voltage and reactive power response of WG4. In terms of WG4, it absorbed more reactive power corresponding to Strategies 1 and 2, since DFIGs are required to maintain terminal voltage at $1 \mathrm{pu}$, where its steady-state voltage is substantially higher during unity power factor operation due to high wind power generation. However, Strategies 3 and 4 require less reactive power, since the wind generators located at close proximity to distribution transformer (i.e. WG1) have responded to voltage variations with substantial reactive power response than WG4. 


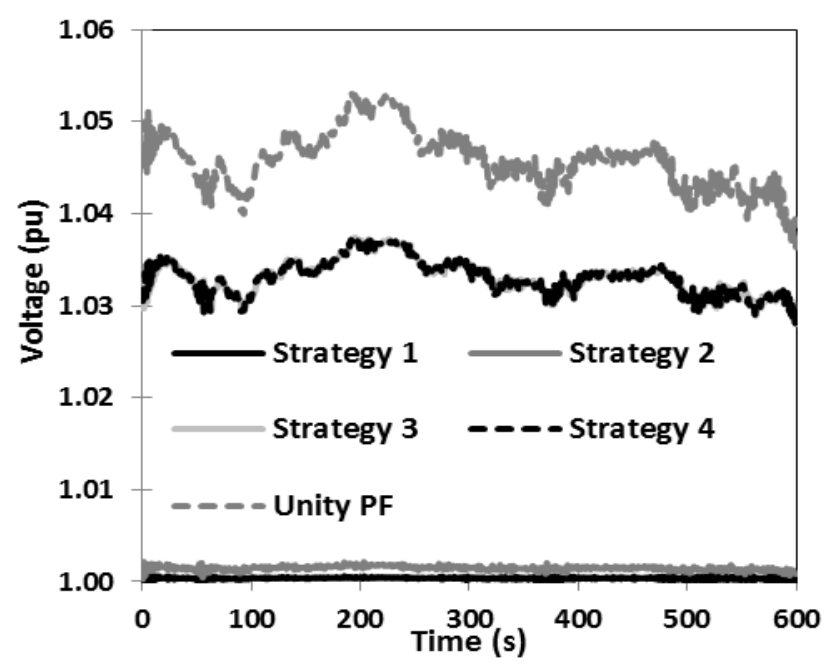

(a)

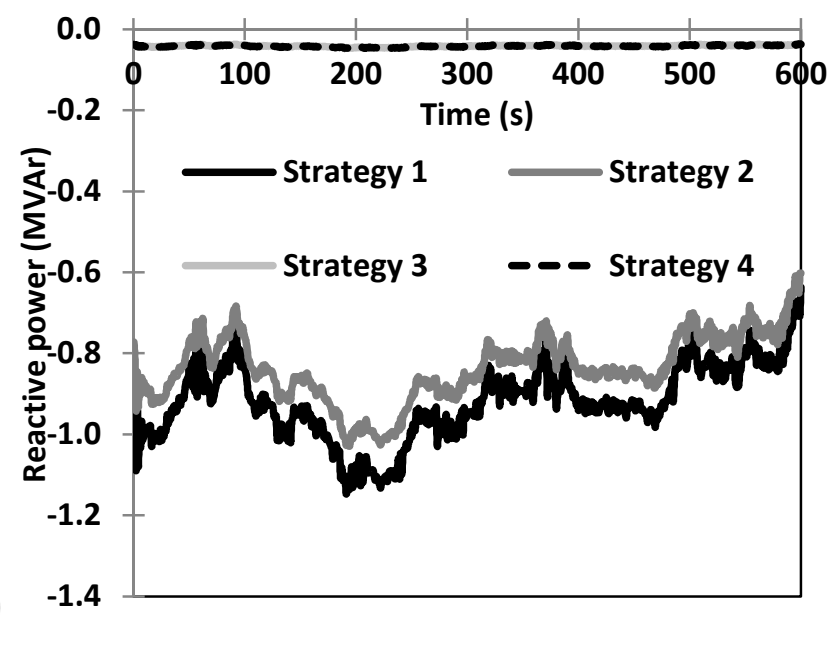

(b)

Figure 13: Dynamic performance of WG4; (a) Voltage at bus 4, (b) Reactive Power.

The droop control strategies have illustrated different reactive power response characteristics during dynamic operating conditions. In particular, WG1 has indicated a large reactive power response compared to WG4 for Strategies 3 and 4. However for Strategies 1 and 2, WG4 has shown a significantly higher reactive power response than Strategies 3 and 4 . Although, Strategies 1 and 2 indicate a low steady-state voltage profile, their voltage control performances are significantly influenced by the activation voltage and subsequently lead to substantially uneven reactive power responses between DFIGs installed in the distribution feeder. For example, if the activation voltage is set at $1.025 \mathrm{pu}$ for droop control Strategy 1 , it leads to an average reactive power difference of $0.53 \mathrm{pu}$ between WG1 and WG4, while this difference is only 0.38 pu when droop activation voltage is set at $1 \mathrm{pu}$. This is due to the fact that when activation voltage is set at $1.025 \mathrm{pu}$, it activates the voltage controllers only at remote locations in the feeder, hence closest wind generator don't participate in voltage control as their respective bus voltage is less than activation voltage (i.e. $1.025 \mathrm{pu}$ ). This ultimately results in large reactive power difference between wind generators located at close proximity to distribution transformer and remote locations in the feeder. Therefore, it is beneficial to determine the droop based on the network characteristics as given in (8), while the droop activation voltage can be set at the nominal system voltage for all generators in the distribution feeder.

\subsection{Influence of the Reactive Power Capability on Droop Control}

Reactive power capability is also an influential factor for distribution feeder voltage control. The impact of reactive power capability on voltage control is graphically illustrated in Figure 14. 


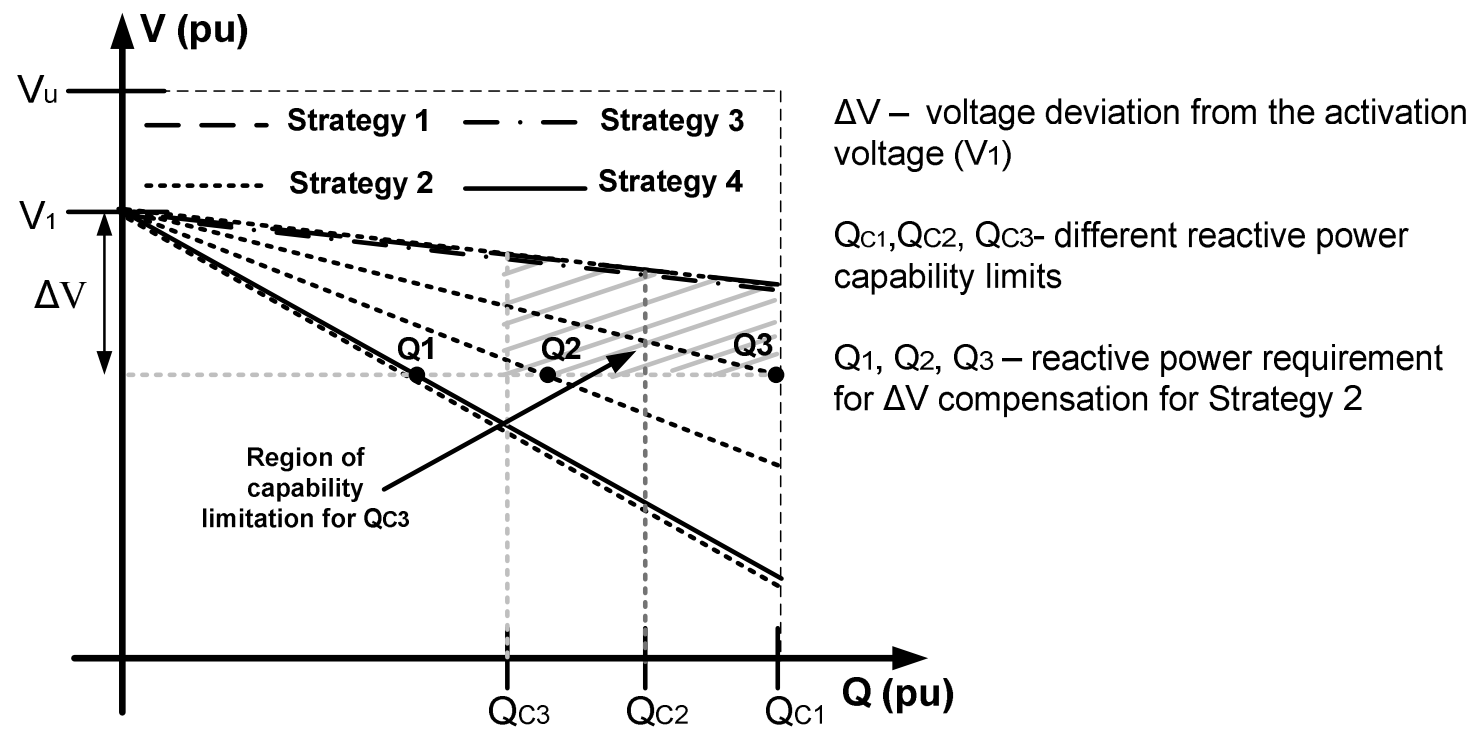

Figure 14: Impact of reactive power capability on droop control strategies.

It can be observed that different droop control strategies require different reactive power requirements (i.e. $\mathrm{Q}_{1}, \mathrm{Q}_{2}, \mathrm{Q}_{3}$ ) to compensate for the $\Delta \mathrm{V}$ voltage difference. If the reactive power capability is less than the requirement, the DFIG would not be able to control the voltage within desired voltage limits during dynamic operating conditions. For example, if the DFIG reactive power capability is limited to $\mathrm{Q}_{\mathrm{c} 3}$, it would not be able to deliver $\mathrm{Q}_{2}$ and $\mathrm{Q}_{3}$ reactive power requirements to compensate $\Delta \mathrm{V}$ assuming DFIGs are configured for Strategy 2 (see the shaded area of Figure 14). Therefore, the reactive power capability of the DFIG is a significant factor in regulating the voltage of the feeder.

The influence of the reactive power capability on droop control was investigated considering the droop control Strategy 1 and observed large voltage variations when the reactive power capability of the DFIG was reduced from its maximum capability (see Figure 15). For example, when only GSC reactive power capability is used WG4 indicates a voltage variation of $1.6 \%$ and this was reduced to $0.1 \%$ when the RSC and GSC reactive power capability was used for voltage control. 


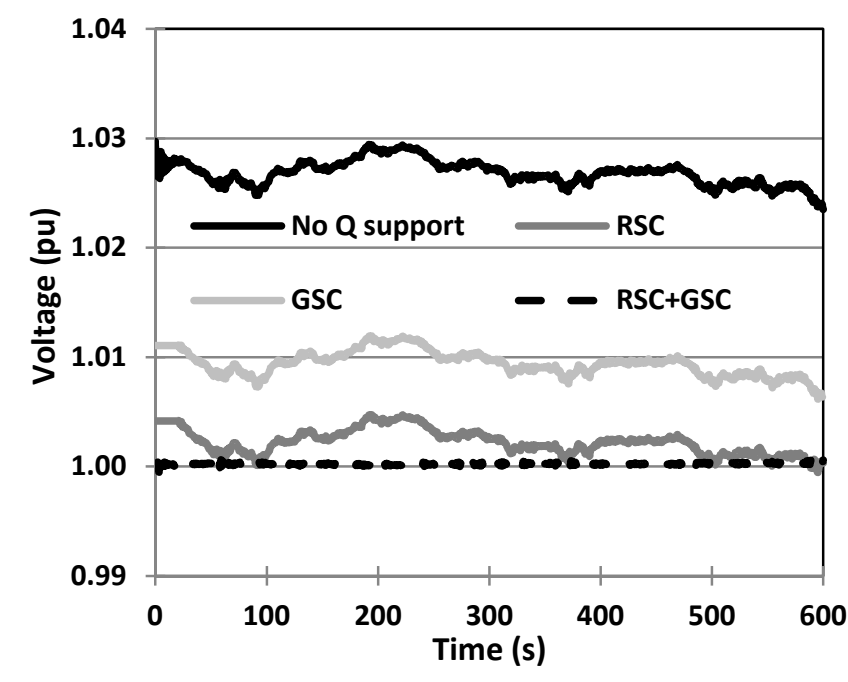

(a)

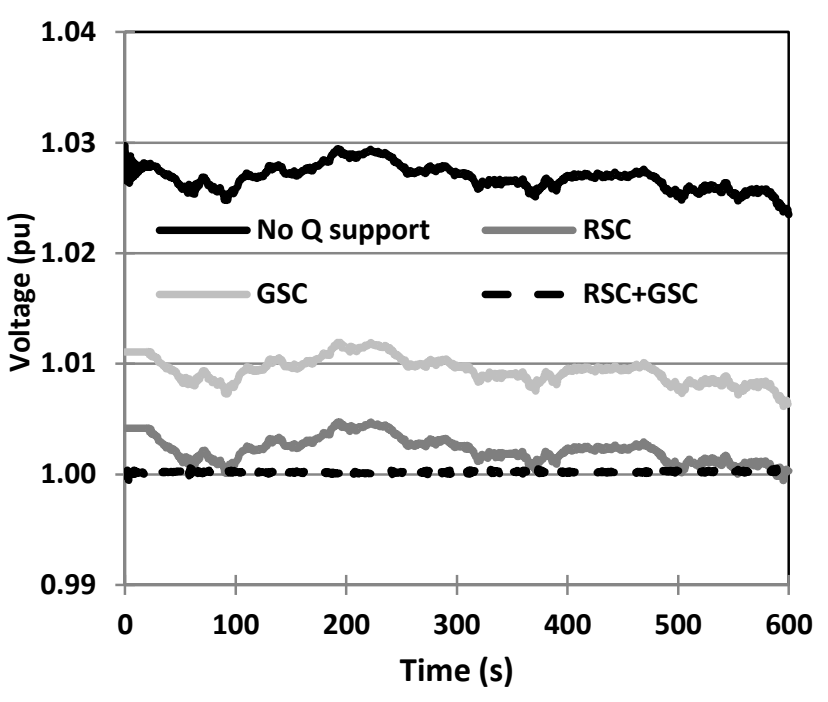

(b)

Figure 15: Comparison of voltage variations under different reactive power capabilities; (a) WG1, (b) WG4.

Table 4: Reactive Power Output of DFIGs for under Reactive Power Capabilities

\begin{tabular}{c|c|c|c|c}
\hline \hline \multirow{2}{*}{$\begin{array}{c}\text { Reactive Power } \\
\text { Capability }\end{array}$} & WG1 & WG2 & WG3 & WG4 \\
\cline { 2 - 5 } & -0.73 & -0.73 & -0.73 & -0.73 \\
\hline RSC & -0.54 & -0.54 & -0.54 & -0.54 \\
\hline GSC & -0.54 & -0.82 & -0.89 & -0.92 \\
\hline \hline
\end{tabular}

According to Table 4, when wind generators are equipped with both RSC and GSC reactive power capability, the average reactive power requirement for each generator is different from each other. Furthermore, the reactive power requirement for WG1 substantially increased with only RSC reactive power capability compared to extended reactive power capability (i.e. RSC and GSC). This is due to the fact that when only RSC reactive power is utilised, reactive power capability is not sufficient to meet the reactive power requirement to mitigate voltage fluctuations at remote wind farms (i.e. WG4), hence high voltage fluctuations are still apparent at wind farm busses closer to distribution transformer (i.e. WG1). Therefore, WG1 is required to inject more reactive power to mitigate voltage fluctuations than extended reactive power (i.e. RSC + GSC) scenario. Ultimately all wind farms have reached their reactive power limit, thus all wind farms have indicated same average reactive power output. However, large voltage variations can still be observed at WG1 with only RSC capability. Conversely, when extended reactive power capability (i.e. RSC + GSC) is employed at wind farms, remote wind farms have sufficient reactive power 
capability to mitigate voltage fluctuations and manage the voltage profile within the grid-code limit. Therefore, wind farms closer to distribution transformer require less reactive power to maintain voltage within stipulated limits. This reveals the importance of acquiring extended reactive power capability for the DFIG. In particular, remotely located wind generators will require a substantially high reactive power provision for voltage control, hence they will benefit from the proposed extended reactive power controller for the DFIG.

\section{Conclusions}

The extended reactive power capability of the DFIG was examined in this paper in order to improve the network stability and voltage management during transient faults and dynamic operating conditions. A novel coordinated reactive power controller was designed for the DFIG considering RSC and GSC reactive power capability characteristics. This study has shown that a substantial improvement can be achieved in voltage recovery during transient disturbances by using the extended reactive power capability of the DFIG. In particular, partially loaded DFIGs are capable of providing a higher reactive power output during system contingencies for network stability enhancement. Moreover, a number of droop control strategies were also investigated, and it was been shown that droop control strategy highly influences the reactive power requirement and feeder voltage management. The proposed feeder adaptive droop control method can be used to determine the droop settings for the distribution feeder, since it requires minimum feeder information and ultimately reactive power burden can be effectively distributed among the generator units installed along the distribution feeder. Furthermore, the study has shown that a lesser reactive power capability for the DFIG will significantly impact on voltage control performance of the network adaptive droop control strategy.

At present, commercially available wind generator systems provide limited reactive power support based on RSC capability, however extended reactive power support has not been effectively utilised in many DFIGs. Therefore, it is essential to incorporate these extended reactive power capabilities for DFIG wind generators in the future in order to provide enhanced network support. 


\section{Appendix: 1.5 MW DFIG Parameters}

1.5 MW DFIG parameters: rated stator voltage: $0.69 \mathrm{kV}$; rated rotor voltage: $1863 \mathrm{~V}$; rated apparent power: 1,667 kVA; rated speed: $1800 \mathrm{rpm}$; no. pole pairs: 2; stator resistance: $0.01 \mathrm{pu}$; stator reactance: $0.1 \mathrm{pu}$; rotor reactance: $0.1 \mathrm{pu}$; rotor resistance: $0.01 \mathrm{pu}$; magnetising reactance: $3.5 \mathrm{pu}$; generator inertia: $75 \mathrm{kgm}^{2}$; turbine inertia: 4,052,442 $\mathrm{kgm}^{2}$; shaft stiffness: $83,000,000 \mathrm{Nm} / \mathrm{rad}$. 


\section{References}

[1] S. Engelhardt, I. Erlich, C. Feltes, J. Kretschmann, F. Shewarega, Reactive power capability of wind turbines based on doubly fed induction generators, IEEE Trans. Energy Convers. 26(1) (2011), pp. 364-372.

[2] T. Lund, P. Sorensen, J. Eek, Reactive power capability of a wind turbine with doubly fed induction generator, Wind Energy. 10(4) (2007), pp. 379-394.

[3] M. Kayikci, J.V. Milanovic, Reactive Power Control Strategies for DFIG-Based Plants, IEEE Trans. Energy Convers. 22(2) (2007), pp. 389-396.

[4] L.G. Meegahapola, T. Littler, D. Flynn, Decoupled-DFIG fault ride-through strategy for enhanced stability performance during grid faults, IEEE Trans. Sust. Energy. 1(3) (2010), pp. 152-162.

[5] S. Foster, L. Xu, B. Fox, Coordinated reactive power control for facilitating fault ride through of doubly fed induction generator- and fixed speed induction generator-based wind farms, IET Renew. Power Gen. 4(2) (2010), pp. 128-138.

[6] L. Meegahapola, S. Durairaj, D. Flynn, B. Fox, Coordinated utilisation of wind farm reactive power capability for system loss optimisation, European Trans. Elec. Power. 21(1) (2011), pp. 40-51.

[7] R. J. Konopinski, P. Vijayan, V. Ajjarapu, Extended Reactive Capability of DFIG Wind Parks for Enhanced System Performance, IEEE Trans. Power Syst. 24(3) (2009), pp. 1346-1355.

[8] L. Meegahapola, B. Fox, T. Littler, D. Flynn, Multi-Objective Reactive Power Support from Wind Farms for Network Performance Enhancement, Int Trans. Electr Energy Syst. 23(1) (2013), pp. 135-150.

[9] M.A. Mahmud, M.J. Hossain, H.R. Pota, A.B.M. Nasiruzzaman, Voltage control of distribution networks with distributed generation using reactive power compensation, IECON 2011 - 37th Annual Conference on IEEE Industrial Electronics Society, Melbourne, Australia, 2011.

[10] M. Oshiro, K. Tanaka, A. Uehara, T. Senjyu, Y. Miyazato, A. Yona, T. Funabashi, Optimal voltage control in distribution systems with coordination of distribution installations, Int $\mathrm{J}$ Electr Power Energy Syst. 32 (10) (2010), pp. 1125-1134.

[11] E. Demirok, D. Sera, P. Rodriguez, R. Teodorescu, Enhanced local grid voltage support method for high penetration of distributed generators, IECON 2011 - 37th Annual Conference on IEEE Industrial Electronics Society, Melbourne, Australia, 2011.

[12] N.W. Miller, W.W. Price, and J.J Sanches-Gasca, Dynamic modeling of GE 1.5 and 3.6 wind turbine generators, ver. 3.0, GE, 2003.

[13] A.M. Kassem, K.M. Hasaneen, A.M. Yousef, Dynamic modeling and robust power control of DFIG driven by wind turbine at infinite grid, Int J Electr Power Energy Syst. 44 (1) (2013), pp. 375-382. 
[14] IEEE Recommended Practice for Excitation System Models for Power System Stability Studies, IEEE Standard 421.5-2005, Apr. 2006.

[15] Y.L. Abdel-Magid, M.A. Abido, A.H. Mantaway, Robust tuning of power system stabilizers in multi-machine power systems, IEEE Trans. Power Syst., 15 (2000), pp. 735-740.

[16] M.A. Abido, A novel approach to conventional power system stabilizer design using tabu search, Int. J. of Elect. Power Energy Syst., 21 (1999), pp. 443-454.

[17] L. Meegahapola, D. Flynn, Impact on transient and frequency stability for a power system at very high wind penetration, IEEE Power Engineering Society General Meeting, Minneapolis, USA, 2010.

[18] L. Meegahapola, D. Flynn, T. Littler, Transient stability analysis of a power system with high wind penetration, UPEC 2008, Padova, Italy, 2008.

[19] P. Kundur, Power Systems Stability and Control. New York: McGraw-Hill, 1994.

[20] Y. Ling, X. Cai, Rotor current dynamics of doubly fed induction generators during grid voltage dip and rise, Int J Electr Power Energy Syst. 44 (1) (2013), pp. 17-24.

[21] M. Rahimi, M. Parniani, Dynamic behaviour analysis of doubly-fed induction generator wind turbines - The influence of rotor and speed controller parameters, Int J Electr Power Energy Syst. 32 (5) (2010), pp. 464-477.

[22] S. Persaud, B. Fox, D. Flynn, Impact of remotely connected wind turbines on steady-state operation of radial distribution networks, IET Gen. Transmi. and Distri., 147(3) (2000), pp. 157-163. 